\title{
The Africa Regional SGBV Network Learning Brief Series: Learning updates from Kenya (Brief \#4)
}

Population Council

Follow this and additional works at: https://knowledgecommons.popcouncil.org/departments_sbsr-rh

Part of the Demography, Population, and Ecology Commons, Domestic and Intimate Partner Violence Commons, Family, Life Course, and Society Commons, International Public Health Commons, and the Maternal and Child Health Commons

How does access to this work benefit you? Let us know!

\section{Recommended Citation}

"The Africa Regional SGBV Network Learning Brief Series: Learning updates from Kenya (Brief \#4)." Nairobi: Population Council, 2016. 


\section{The Africa Regional SGBV Network Learning Brief Series}

Fostering a Multisectoral Response to Violence Against Children in East and Southern Africa

\section{Learning Updates from Kenya (Brief \#4)}

According to Kenya's 2010 Violence Against Children (VAC) survey, $32 \%$ of females and $18 \%$ of males in Kenya suffer some form of sexual abuse before they turn 18. Although about a quarter would like to receive care for the abuse, most do not tell anyone about it, and very few (3\%) end up receiving care afterward. The Africa Regional Sexual and Gender Based Violence (SGBV) Network, set up in 2006, is addressing VAC in four countries. This Learning Brief is one in a series of five that share critical, initial understandings of VAC that will help us respond more effectively to the problem.

\section{The Gender-Based Recovery Centre, Kenyatta National Hospital}

In an attempt to improve the reporting of child sexual abuse (CSA) and children's access to services, the Gender-Based Violence Recovery Center (GBVRC) of Kenyatta National Hospital (KNH) in Nairobi, Kenya, is exploring the feasibility of routine screening for CSA in health care and school settings. $\mathrm{KNH}$ is the oldest and

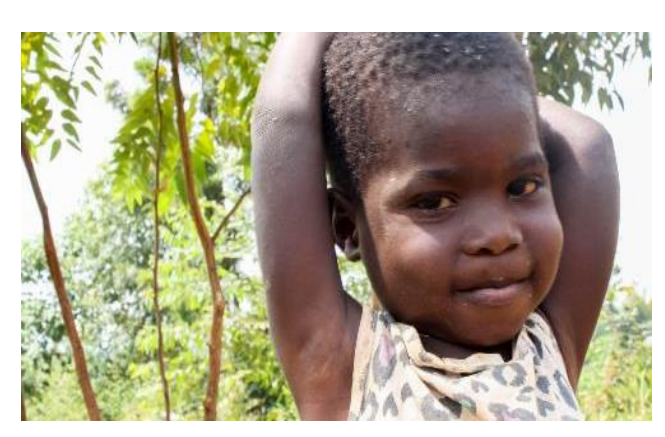

MANY CHILDREN ARE

LEFT ALONE AND

VULNERABLE AT HOME

BECAUSE THEIR WORKING

PARENTS CAN'T AFFORD

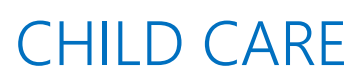

largest public referral, teaching, and research hospital in the East and Central African region. The GBVRC at $\mathrm{KNH}$ is one of the best-known and most commonly utilized one-stop response centers for SGBV in Kenya. Initial findings show significant support for screening for CSA amongst people who work with children in Nairobi. 


\section{What We're Already Learning}

Here's what we're learning about the context for screening children in urban, low-income primary schools and health facilities.

- CSA is viewed as a major predicament in urban poor areas on Nairobi.

\section{SCREENING FOR CHILD SEXUAL ABUSE IS SEEN AS AN URGENT NEED IN $\mathrm{NAIROB|}$}

- Sexually abused girls and boys in this setting often face ongoing, continuous abuse, rather than 'one-time' or rare exposure to sexual abuse.

- Removing children from sexually abusive situations is rarely feasible. Very few rescue centers or shelters for abused children exist and, where they do, they often only permit short-term stays. In many cases, the adult who is abusing the child - if they are the child's care giver - simply relocates with the abused child when they are found out.

- Poverty often leads parents to reach informal financial settlements with perpetrators, rather than involve the judicial system. A weak judicial system gives parents little incentive to take legal action.

- Support for CSA screening is unanimous and strong; parents of abused and non-abused children, representatives of the Department of Children's Services, National Council for Children's Services, Ministry of Health, Ministry of Education, and ParentTeacher Association members are all supportive.

PARENTS OF CHILD

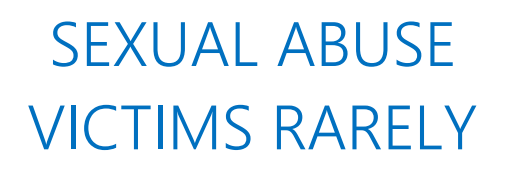

- There was general consensus that teachers should not conduct screening in schools; understaffing and confidentiality were raised as concerns.

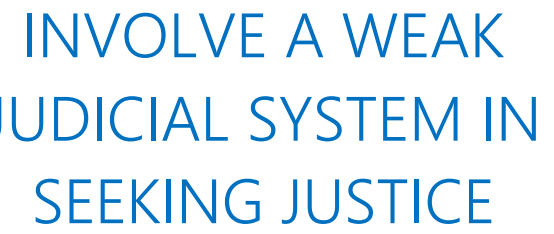




\section{What We're Doing about It}

In collaboration with the Population Council, the GBVRC is developing a response to CSA that takes into account these contextual realities. The intervention will involve dialogues with parents and children in primary schools. The aim is to get people talking about abuse in their community, the consequences of such abuse and what stops girls and boys or their parents from seeking care for abuse. They will also discuss school-based screening for CSA. Health care providers will be trained in Trauma-Focused Cognitive Behavioral Therapy - an evidence-based treatment that has been used successfully with youth and families in low-resource settings who experience ongoing or continuous traumas. Routine screening of girls and boys for CSA (by trained psychologists) in schools and in the Casualty Department of Kenyatta National Hospital will be tested, coupled with child-friendly referrals to the GBVRC for comprehensive care.

Since 2006, the Africa Regional SGBV Network has worked to build effective responses to SGBV in low-resource settings, focusing on those who have experienced violence, as well as on violence prevention. From 2014-2017, the network is addressing the needs of two vulnerable populations - children and refugees.

(c) 2016 The Population Council, Inc.

Network Contact:

Population Council

General Accident Insurance House

Ralph Bunche Road

Nairobi, Kenya

$\mathrm{T}:+254202713480$

E: info.nairobi@popcouncil.org
KNH Contact:

Gender-Based Violence Recovery

Centre

Kenyatta National Hospital

Hospital Road, Upperhill

Nairobi 00202

$\mathrm{T}:+254729406939$

E: mgamak@yahoo.com

We gratefully acknowledge the support of the Regional Team for Sexual and Reproductive Health and Rights, Embassy of Sweden, Lusaka, Zambia.
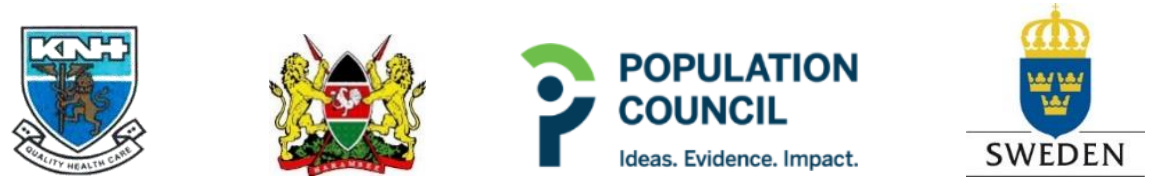